\title{
Increasing protein production by directed vector backbone evolution
}

Felix Jakob ${ }^{1,2 \dagger}$, Christian Lehmann ${ }^{1 \dagger}$, Ronny Martinez ${ }^{1}$ and Ulrich Schwaneberg ${ }^{1,2^{*}}$

\begin{abstract}
Recombinant protein production in prokaryotic and eukaryotic organisms was a key enabling technology for the rapid development of industrial and molecular biotechnology. However, despite all progress the improvement of protein production is an ongoing challenge and of high importance for cost-effective enzyme production. With the epMEGAWHOP mutagenesis protocol for vector backbone optimization we report a novel directed evolution based approach to increase protein production levels by randomly introducing mutations in the vector backbone. In the current study we validate the epMEGAWHOP mutagenesis protocol for three different expression systems. The latter demonstrated the general applicability of the epMEGAWHOP method. Cellulase and lipase production was doubled in one round of directed evolution by random mutagenesis of pET28a(+) and pET22b(+) vector backbones.

Protease production using the vector pHY300PLK was increased $\sim 4$-times with an average of $\sim 1.25$ mutations per $\mathrm{kb}$ vector backbone. The epMEGAWHOP does not require any rational understanding of the expression machinery and can generally be applied to enzymes, expression vectors and related hosts. epMEGAWHOP is therefore from our point of view a robust, rapid and straight forward alternative for increasing protein production in general and for biotechnological applications.
\end{abstract}

Keywords: Directed evolution; epMEGAWHOP; Recombinant protein production; Lipase expression; Cellulase expression; Protease expression

\section{Introduction}

Development of cloning and expression technologies to produce recombinant proteins in prokaryotic and eukaryotic organisms enabled the production of numerous enzymes for diagnostic and industrial applications such as food, leather, textile or detergent industry (Kirk et al. 2002; Rai and Padh 2001). Recombinant production of proteins in prokaryotic hosts is commonly increased by optimization of cultivation or fermentation conditions (temperature, aeration, media composition and/or the fermentation type, such as batch, fed-batch or continuous), codon optimization (Gustafsson et al. 2004; Li et al. 2003), co-expression of chaperones (Thomas et al. 1997), increasing the lifetime of mRNA (Terpe 2006), exchanging/modifying promoters and/or signal peptides (Caspers et al. 2010; Degering et al. 2010;

\footnotetext{
* Correspondence: u.schwaneberg@biotec.rwth-aachen.de

†Equal contributors

'Lehrstuhl für Biotechnologie, RWTH Aachen University, Worringerweg 1, Aachen 52074, Germany

${ }^{2}$ DWI an der RWTH Aachen e.V, Forckenbeckstraße 50, Aachen 52056, Germany
}

Xue et al. 1997), optimizing the distance between promoter and gene (Brosius et al. 1985), protein fusion technology (e.g. NusA, maltose-binding protein [MBP] or glutathione S-transferase [GST]) (Cabrita et al. 2006), or by metabolic engineering (Heyland et al. 2011; Kabisch et al. 2012).

Directed evolution has become a standard approach to tailor enzyme properties such as activity, solubility, temperature or organic solvent resistance to often nonnatural requirements in industrial production. In directed enzyme evolution campaigns enzyme production is often unexpectedly increased in initial rounds (Tee and Schwaneberg 2007). A typical directed evolution experiment comprises three iterative steps of (1) diversity generation, (2) screening to identify improved variants out of a large pool of variants, and (3) isolating the genes encoding for improved variants (Shivange et al. 2009). The screening system plays a pivotal role for reliably identifying improved enzyme variants. Among the screening formats, 96-well microtiter plates are commonly used in directed evolution experiments with 
throughputs of a few thousand variants per round (Tee and Schwaneberg 2007). Recent developments in high throughput screening technologies comprise throughputs of $10^{6}-10^{8}$ based on flow cytometry (Ruff et al. 2012; $\mathrm{Tu}$ et al. 2011) and microfluidics (Fallah-Araghi et al. 2012; Kintses et al. 2012). In this work we report a novel strategy to increase enzyme production in bacterial hosts (E. coli and B. subtilis), which is based on the 'megaprimer PCR of whole plasmid method' (MEGAWHOP) (Miyazaki 2003; Miyazaki 2011). In our modified error-prone MEGAWHOP method (epMEGAWHOP) mutated vector backbone libraries were generated by amplification under error-prone PCR conditions using non-mutated genes as megaprimers, and subsequently screened for increased activity. The general applicability of the developed strategy was proven by using three enzymes (CelA2, BSLA and subtilisin Carlsberg) in three different vector-systems (pET28a (+), pET22b(+) and pHY300PLK) and two different and industrially important expression hosts ( $E$. coli (Baneyx 1999; Jana and Deb 2005) and B. subtilis (Terpe 2006; Westers et al. 2004)). In all three cases an increased enzyme production was obtained with optimized vector backbones.

\section{Materials and methods}

All chemicals were of analytical-reagent grade or higher quality and were purchased from Carl Roth $\mathrm{GmbH}$ (Karlsruhe, Germany), Sigma-Aldrich (Hamburg, Germany) and AppliChem (Darmstadt, Germany). Enzymes were purchased from New England Biolabs (Beverly, USA) and Fermentas (St. Leon-Rot, Germany). Oligonucleotides were purchased from Eurofins MWG Operon (Ebersberg, Germany) in salt-free form. Plasmid extraction and PCR purification kits were purchased from MachereyNagel (Düren, Germany). Microtiter plates (Greiner Bio-One $\mathrm{GmbH}$, Frickenhausen, Germany) were incubated in a Multitron II Infors shaker (Infors AG, Bottmingen, Switzerland). DNA concentrations were quantified using a NanoDrop photometer (ND-1000, NanoDrop Technologies, Wilmington, USA). A Mastercycler gradient (Eppendorf, Hamburg, Germany) and thin-wall PCR tubes (Multi ultra-tubes; $0.2 \mathrm{~mL}$; Carl Roth, Germany) were used in all PCRs.

\section{Strains and plasmids}

E. coli DH5 $\alpha$, E. coli BL21-Gold (DE3) (purchased from Agilent Technologies; Santa Clara, USA) and B. subtilis DB104 (Kawamura and Doi 1984) were used in this study as hosts for DNA manipulation and recombinant protein production. For construction of the expression vectors for the E. coli strains (DH5 $\alpha$; BL21-Gold (DE3)), and the plasmids pET28a $(+)$ or pET22b $(+)$ (Novagen; Darmstadt, Germany) were used. In case of B. subtilis DB104 the shuttle vector pHY300PLK (Takara Bio Inc.,
Shiga, Japan) was employed. Chemically competent $E$. coli DH5 $\alpha$ and E. coli BL21-Gold (DE3) cells with determined transformation efficiencies of $3 \times 10^{7}$ and $3 \times 10^{6}$ $\mathrm{cfu} / \mu \mathrm{g}$ pUC19, respectively, were prepared in-house using the rubidium chloride method (Hanahan 1983). Transformation of B. subtilis DB104 was performed using a recently developed method which is based on natural competence (Vojcic et al. 2012).

\section{Gene cloning, construction of expression vectors, and sequencing \\ CelA2}

The parent celA2 (GenBank: JF826524.1; (Lehmann et al. 2012)) was ordered as a synthetic gene from GeneArt (Regensburg, Germany) with an optimized codon usage for E. coli (GenBank submission number ID1624106) flanked by an NcoI and an EcoRI restriction site. Additionally, celA2 contains an N-terminal His-tag, followed by a TEV-protease sequence. After double digestion with $\mathrm{NcoI}$ and EcoRI, the fragment was subcloned into pET28a $(+)$. The generated construct, named pET28a(+)-CelA2, was transformed into E. coli $\mathrm{DH} 5 \alpha$ and sequenced to exclude mutations.

\section{Bacillus subtilis lipase $A$ (BSLA)}

After double digestion of the parent Bacillus subtilis lipase A (BSLA) (GenBank: JX048066.1) with NdeI and XhoI, the fragment was subcloned using T4 DNA ligase into pET22b $(+)$. The resultant recombinant plasmid, named pET22b(+)-BSLA, contains a C-terminal His-tag and a pelB leader sequence. The plasmid construct was transformed into E. coli DH5 $\alpha$ and sequenced to exclude mutations.

\section{Subtilisin Carlsberg}

After double digestion of a subtilisin Carlsberg variant (GenBank: HM147766.1, harboring the silent mutations C479G, T480C, G482A, G869A, T1052C and G1055C) with $B a m H I$ and $X m a \mathrm{I}$, the gene was subcloned into pHY300PLK using T4 DNA ligase. The resulting recombinant plasmid, named pHYscarlsberg was transformed into E. coli $\mathrm{DH} 5 \alpha$ and sequenced to exclude mutations.

DNA sequencing of all three recombinant plasmids was conducted at Eurofins MWG Operon (Ebersberg, Germany) and Clone Manager 9 Professional Edition (Sci-Ed software, Cary, USA) was used for all sequence alignments.

\section{Generation of error-prone MEGAWHOP libraries}

Megaprimers for each target gene were generated by PCR under standard conditions. The amplification of celA2 and BSLA was performed using unmodified DNA primers 5'-GTTATTGCTCAGCGGTGGCAGCAGC-3' and 5'-TAATACGACTCACTATAGGGGAATTGTGAG 
CGG-3' (5 $\mu \mathrm{M}$ each) binding in the T7 promoter and terminator region. The amplification of the subtilisin Carlsberg gene includes promoter, pre- and pro-sequence and was performed using unmodified DNA primers 5'CAGATTTCGTGATGCTTGTCAGG-3' and 5'-CGTT AAGGGATCAACTTTGGGAG-3' (5 $\mu \mathrm{M}$ each). For the PCR $\left(98^{\circ} \mathrm{C}\right.$ for $30 \mathrm{sec}$, one cycle; $98^{\circ} \mathrm{C}, 15 \mathrm{sec} / 63^{\circ} \mathrm{C}$, $15 \mathrm{sec} / 68^{\circ} \mathrm{C}, 2 \mathrm{~min}($ celA2) or $30 \mathrm{sec}$ (BSLA, subtilisin Carlsberg), 25 cycles; $68^{\circ} \mathrm{C}$ for $10 \mathrm{~min}$, one cycle), PfuS DNA polymerase $(2.5 \mathrm{U})$, dNTP mix $(10 \mathrm{mM})$, template (pET28a(+)-CelA2, pET22b(+)-BSLA and pHYscarlsberg: $30 \mathrm{ng} / \mu \mathrm{L}$ ) were used. The PCR products (megaprimers) were purified using a PCR purification kit.

For the epMEGAWHOP PCR $\left(72^{\circ} \mathrm{C}\right.$ for $5 \mathrm{~min}$, one cycle; $94^{\circ} \mathrm{C}$ for $90 \mathrm{sec}$, one cycle; $94^{\circ} \mathrm{C}, 45 \mathrm{sec} / 60^{\circ} \mathrm{C}$, $45 \mathrm{sec} / 72^{\circ} \mathrm{C}, 5 \mathrm{~min}, 25$ cycles; $72^{\circ} \mathrm{C}$ for $10 \mathrm{~min}$, one cycle), Taq DNA polymerase (2.5 U), dNTP mix (10 mM) together with plasmid template $(\mathrm{pET} 28 \mathrm{a}(+)-\mathrm{CelA} 2$, pET22b(+)-BSLA or pHYscarlsberg: $120 \mathrm{ng}$ ), megaprimer (pET28a(+)-CelA2, pET22b(+)-BSLA or pHYscarlsberg: $550 \mathrm{ng}$ ) and $0.05 \mathrm{mM} \mathrm{Mn}^{2+}$ were used. Following the epMEGAWHOP PCR, DpnI digestion $(20 \mathrm{U})$ of the template was performed overnight at $37^{\circ} \mathrm{C}$. The epMEGAWHOP PCR product was transformed into E. coli $\mathrm{DH} 5 \alpha$. All colonies from the agar plates were used for plasmid isolation and subsequently transformed into their expression host. The plasmids pET28a(+)-CelA2 and pET22b(+)-BSLA were transformed in E. coli BL21-Gold (DE3) and pHYscarlsberg was transformed in B. subtilis DB104.

\section{Indicator plates for pre-screening}

In all three screening systems a halo formation can be used to semi-quantify enzymatic activity as indicator for enzyme production.

\section{Detection of cellulolytic activity}

Azo-CarboxyMethyl-Cellulose (Azo-CM-Cellulose, Megazyme, Bray, Ireland) was used as substrate for determining cellulolytic activity (Hughes et al. 2006). LB agar plates supplemented with $0.125 \%(\mathrm{w} / \mathrm{v})$ Azo-CM-Cellulose, $50 \mu \mathrm{g} / \mathrm{mL}$ kanamycin and $0.1 \mathrm{mM}$ isopropyl-thio- $\beta-\mathrm{D}$ galactoside (IPTG) were used as indicator plates for prescreening.

\section{Detection of lipolytic activity}

Tributyrin was used as substrate for lipolytic activity detection (Alquati et al. 2002). LB agar plates supplemented with $100 \mu \mathrm{g} / \mathrm{mL}$ ampicillin, 1.5\% (v/v) tributyrin, $0.15 \%(\mathrm{w} / \mathrm{v})$ gum arabic were used as indicator plates for pre-screening.

\section{Detection of proteolytic activity}

Skim milk was used as substrate for proteolytic activity detection (Sokol et al. 1979). LB agar plates supplemented with $1 \%(\mathrm{w} / \mathrm{v})$ skim milk and $15 \mu \mathrm{g} / \mathrm{mL}$ tetracycline were used as indicator plates for pre-screening.

\section{Expression in microtiter plates Growth conditions and expression of CelA2 in 96-well microtiter plates}

Colonies displaying cellulolytic activity in the indicator agar plates were transferred into 96-well microtiter plates (flat-bottomed, polystyrene plates). Cultivation and enzyme expression in microtiter plates was performed as previously described (Lehmann et al. 2012) and supernatants of lysates were subsequently used for kinetic characterization.

\section{Growth conditions and expression of BSLA in 96-well microtiter plates}

Colonies displaying lipolytic activity in the indicator agar plates were transferred into 96-well microtiter plates (flat-bottomed, polystyrene plates) containing $200 \mu \mathrm{L} \mathrm{LB}$ medium supplemented with $50 \mu \mathrm{g} / \mathrm{mL}$ ampicillin and incubated (pre-culture; $37^{\circ} \mathrm{C}, 900 \mathrm{rpm}, 24 \mathrm{~h}, 70 \%$ humidity). An expression plate contained $150 \mu \mathrm{L}$ auto-induction medium $(1.2 \%(\mathrm{w} / \mathrm{v})$ casein hydrolysate, $2.4 \%(\mathrm{w} / \mathrm{v})$ yeast extract, $0.5 \%(\mathrm{w} / \mathrm{v})$ glycerol, $0.05 \%(\mathrm{w} / \mathrm{v})$ glucose, $0.02 \%$ $(\mathrm{w} / \mathrm{v})$ lactose and potassium phosphate buffer $(90 \mathrm{mM}$; $\mathrm{pH}$ 7.0) was inoculated with the pre-culture $(10 \mu \mathrm{L})$ and incubated (main culture; $37^{\circ} \mathrm{C}, 900 \mathrm{rpm}, 16 \mathrm{~h}, 70 \% \mathrm{hu}-$ midity). After expression, the microtiter plates were centrifuged $\left(4000 \mathrm{~g}, 20 \mathrm{~min}, 4^{\circ} \mathrm{C}\right)$ to separate the cells from the culture supernatant. Using the expression vector $\mathrm{pET} 22 \mathrm{~b}(+)$ including pelB sequence, the activity of BSLA can be detected in the culture supernatant (Funke et al. 2003; Khushoo et al. 2004; Yedavalli and Rao 2013). Culture supernatant, including the BSLA was transferred after centrifugation into a 96-well microtiter plate for further analysis.

\section{Growth conditions and expression of subtilisin Carlsberg in 96-well microtiter plates}

Single colonies of B. subtilis DB104 which show proteolytic activity on LB skim milk agar plates were transferred into flat-bottom microtiter plates (pre-culture plates) containing buffered LB medium (200 $\mu \mathrm{L} ; 1 \%$ $(\mathrm{w} / \mathrm{v})$ tryptone, $0.5 \%(\mathrm{w} / \mathrm{v})$ yeast extract and $1 \%(\mathrm{w} / \mathrm{v})$ sodium chloride, $17 \mathrm{mM}$ potassium dihydrogen phosphate, $72 \mathrm{mM}$ dipotassium hydrogen phosphate, $15 \mu \mathrm{g} /$ $\mathrm{mL}$ tetracycline) and incubated $\left(37^{\circ} \mathrm{C}, 900 \mathrm{rpm}, 18 \mathrm{~h}\right.$, $70 \%$ humidity). The volume of $10 \mu \mathrm{L}$ pre-culture was used to inoculate the main culture $(150 \mu \mathrm{L}$ buffered $\mathrm{LB}$, $37^{\circ} \mathrm{C}, 900 \mathrm{rpm}, 24 \mathrm{~h}, 70 \%$ humidity). After expression, the microtiter plates were centrifuged (4000 g, $20 \mathrm{~min}$, $4^{\circ} \mathrm{C}$ ) to separate cells from secreted protease. The supernatant was transferred into a microtiter plate for further analysis. 


\section{Analysis of the lacl repressor system}

Performance of the lacI repressor system used in the above described growth and assay conditions was analyzed for each pET expression system. CelA2 and BSLA production was performed in $\mathrm{TB}_{\mathrm{kan}}$ - or $\mathrm{LB}_{\mathrm{amp}}$-medium without supplementing IPTG or the induction components glucose and lactose.

\section{Screening systems}

\section{Fluorometric assay for determining cellulolytic activity of} CelA2

Cellulolytic activity was measured using 4-Methylumbelliferyl -ß-D-cellobioside (4-MUC) as a fluorogenic substrate (Boschker and Cappenberg 1994; Chernoglazov et al. 1989). The cultivation and enzyme reaction was performed as recently reported (Lehmann et al. 2012).

\section{Colorimetric assay for determining lipolytic activity of BSLA}

The lipolytic activity of BSLA in the supernatant was determined using $p$-nitrophenyl butyrate $(p \mathrm{NPB})$ (Shirai et al. 1982). The final reaction contained $0.5 \mathrm{mM} p$ nitrophenyl butyrate dissolved in $10 \mu \mathrm{L}$ acetonitril, $180 \mu \mathrm{L}$ triethanolamin buffer $(50 \mathrm{mM} ; \mathrm{pH}$ 7.4) and $10 \mu \mathrm{L}$ of five times diluted supernatant. The release of $p$-nitrophenolate was continuously monitored at $410 \mathrm{~nm}$ in a microtiter plate reader (Tecan Infinite M1000 Pro) for quantifying the BSLA production.

\section{Colorimetric assay for determining proteolytic activity of subtilisin Carlsberg}

Proteolytic activity was determined in a microtiter plate using the synthetic peptide substrate succinyl-L-Ala-LAla-L-Pro-L-Phe- $p$-nitroanilide (suc-AAPF- $p$ NA) (DelMar et al. 1979). Proteolytic reaction of subtilisin Carlsberg was started by supplementing $10 \mu \mathrm{L}$ of the 1:20 diluted supernatant to Tris/ $\mathrm{HCl}(100 \mu \mathrm{L} ; 100 \mathrm{mM}, \mathrm{pH} 7.5)$ containing $1 \mathrm{mM}$ suc-AAPF- $p \mathrm{NA}$. The release of $p$-nitroaniline was continuously monitored at $410 \mathrm{~nm}$ in a microtiter plate reader (Tecan Infinite M1000 Pro) and the determined activity was used for protease quantification.

\section{Sodium dodecyl sulfate polyacrylamide gel electrophoresis (SDS-PAGE)}

The SDS-PAGE for CelA2 was performed using a stacking gel $(5 \%(\mathrm{w} / \mathrm{v})$ acrylamide) and a separating gel $(15 \%$ (w/v) acrylamide) (Laemmli 1970). Proteins in the supernatant (including BSLA or subtilisin Carlsberg) were precipitated with trichloroacetic acid (TCA; 30\% (v/v); $15 \mathrm{~min}$ on ice), resuspended after washing with acetone in Tris/HCl (100 mM; pH 8.0). The proteins in the supernatant after centrifugation of cell lysate (CelA2) as well as the precipitated and resuspended proteins from the cell culture supernatant (BSLA and subtilisin
Carlsberg) were loaded and separated by SDS-PAGE. Subsequently, the SDS-PAGE gel was stained with Coomassie brilliant blue.

\section{Results}

In the first sections the development of the epMEGAWHOP protocol is described and the screening for increased activity of the selected cellulase, lipase and protease. Subsequently, the obtained variants showing increased activity were analyzed in detail to validate the epMEGAWHOP method.

\section{Library generation screening}

Figure 1 shows the scheme of the developed epMEGAWHOP protocol starting from the generation of megaprimers by PCR (Step I). Followed by an amplification of the whole plasmid under error-prone conditions $\left(0.05 \mathrm{mM} \mathrm{Mn}^{2+}\right.$ ) (Step II) and digestion of the methylated template. In (Step III) the resulting circular DNA is transformed into E. coli $\mathrm{DH} 5 \alpha$ cells. The plasmids are subsequently isolated

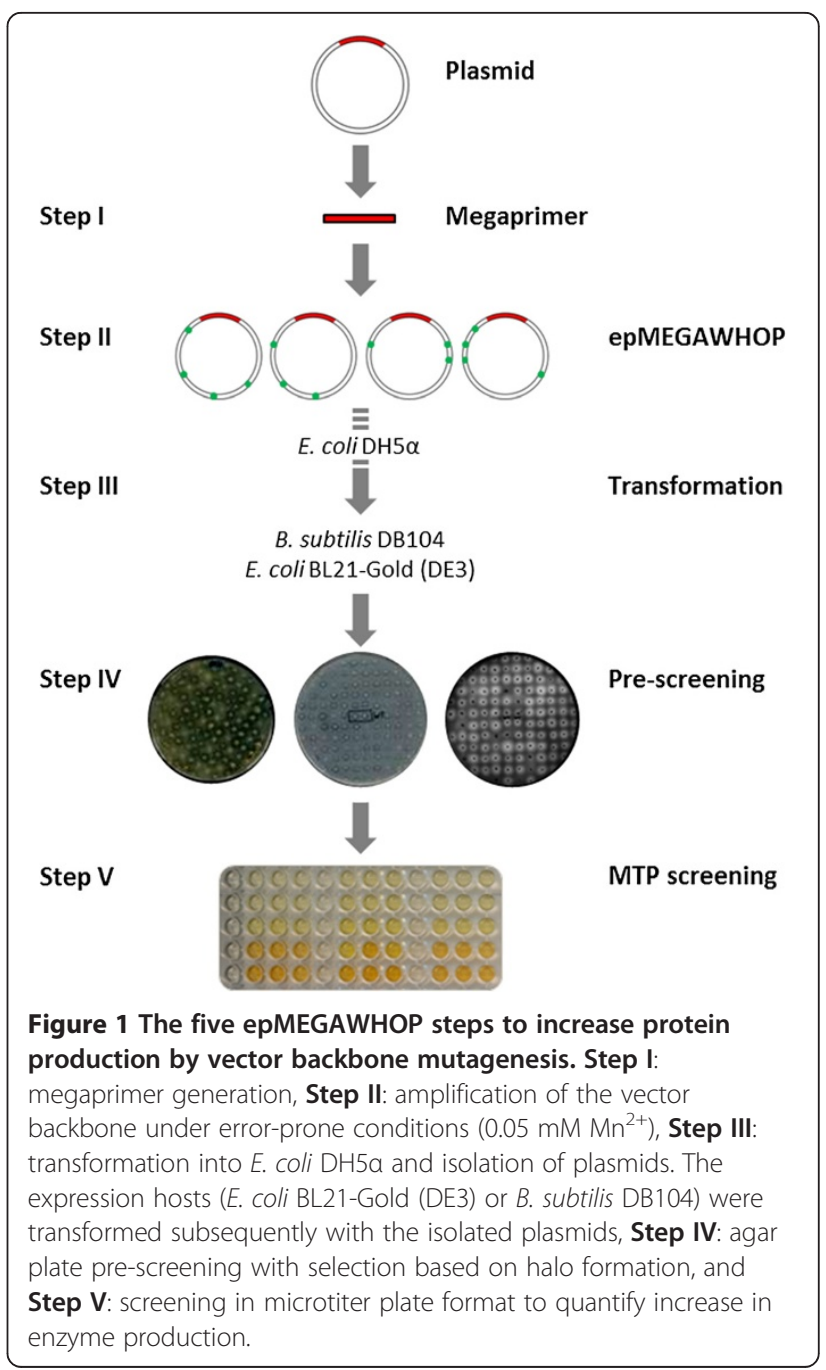


from E. coli $\mathrm{DH} 5 \alpha$ and transformed into the expression host (E. coli BL21-Gold (DE3) or B. subtilis DB104) and grown on indicator plates (Step IV). Colonies showing halos are transferred into microtiter plates for quantification of enzymatic activity (Step V). Table 1 summarizes the expression constructs used for epMEGAWHOP development.

Approximately $1000 \mathrm{CFU}$ were pre-screened using the corresponding agar plate detection systems for all three expression systems. Ninety promising variants were selected based on halo formation and rescreened more precisely in 96-well microtiter plate format. The most promising candidates (one cellulase, one lipase and one protease) were analyzed in detail to confirm that the increased production can be attributed to an optimized vector backbone. For the latter the wild-type genes (CelA2, BSLA and subtilisin Carlsberg) were cloned into the mutated backbone as described under Materials and Methods with subsequent rescreening in three 96-well microtiter plate measurements in which each construct was expressed 8 times per plate.

\section{Activity and expression analysis}

The activity of the three identified variants compared to their parents is shown in Figure 2a. Mutagenized vector backbones of pET28a(+)M1-CelA2 and pET22b(+)M1BSLA showed compared to the respective 'wild-type' a 2-fold increased lipolytic and cellulolytic activity. These activity increases can be correlated to the amount of expressed enzyme which is visualized within a SDSPAGE in Figure 2b. The mutated vector backbone of pHYM1-scarlsberg showed the highest increase in secreted subtilisin Carlsberg production (4-fold increased proteolytic activity). The increased proteolytic activity correlates well with the increase in the protease content (see SDS-PAGE analysis Figure 2a, $\mathrm{b}$; the whole SDS-PAGE picture is available in the Additional file 1: Figure S1).

\section{Analysis of the lacl repressor system}

Expression under inducing and non-inducing conditions was performed to analyze whether the lacI repressor contributes to increased production levels. The constructs pET28a(+)-CelA2 and pET22b(+)-BSLA are under the control of lacI repressor. Figure 3 shows under noninduced conditions a significant difference in activity/ lipase production in the pET22b(+)-BSLA expression vector: the mutated backbone yielded $0.34 \mathrm{U} / \mathrm{mL}$ compared to $0.04 \mathrm{U} / \mathrm{mL}$ of the 'parent' $\mathrm{pET} 22 \mathrm{~b}(+)$. The latter result proves that lacI influences lipase production in pET22b(+)M1-BSLA. Sequencing results confirmed two mutations in lacI (see Table 2). An opposite results was found for the pET28a $(+)-C e l A 2$ and the pET28a(+)M1-CelA2 expression systems in which under non-induced conditions only very low cellulase activities could be determined $(<0.02 \mathrm{U} / \mathrm{mL})$. These results prove that the lacI is an effective repressor even in the optimized vector backbone. Sequencing results confirmed that there are no mutations in the lacI within the pET28a(+)M1-CelA2 expression system (Table 2). In all four constructs the lacI repressor is functional as confirmed by IPTG induction (Figure 3).

\section{Sequence analysis}

Sequence analysis was performed by sequencing the vector backbones and inserts. An average mutation frequency of 1.00-1.25 mutations per $1 \mathrm{~kb}$ plasmid DNA was obtained (Additional file 1: Figure S2) and all inserts did not contain a mutation. Table 2 summarizes positions of mutations in the vector backbones and assigns mutations to functional regions. Interestingly, the antibiotic resistance is mutated in all three vector systems, and functional regions such as the origin of replication (in pET28a(+)M1-CelA2; pHYM1-scarlsberg), promoter (pET28a(+)M1-CelA2), repressor (pET22b(+)M1-BSLA), and terminator (pHYM1-scarlsberg).

\section{Discussion}

The MEGAWHOP method is commonly used for cloning random mutagenesis libraries via whole plasmid PCR into the desired expression vector containing the parent gene (Miyazaki 2011). In general enzyme properties such as activity, substrate specificity or stability are improved in directed evolution experiments employing MEGAWHOP (Agudo et al. 2012; Martinez et al. 2013; Sass et al. 2012). The developed epMEGAWHOP does not aim to improve enzymes properties. epMEGAWHOP aims to increase the enzyme production without altering its properties through vector backbone mutagenesis. The error-prone (ep-) label was placed in front of the MEGAWHOP term to point out the main difference that the vector amplification is performed under error-prone conditions.

Table 1 Overview of the expression systems used for developing and validating the epMEGAWHOP method

\begin{tabular}{lllc}
\hline Expression host & Plasmid & Enzyme & Location of expressed enzyme \\
\hline E. coli BL21-Gold (DE3) & pET28a(+) & Cellulase (CelA2) & Intracellular \\
E. coli BL21-Gold (DE3) & pET22b(+) & Lipase A (BSLA) & Periplasmatic \\
B. subtilis DB104 & pHY300PLK & Protease (subtilisin Carlsberg) & Extracellular \\
\hline
\end{tabular}




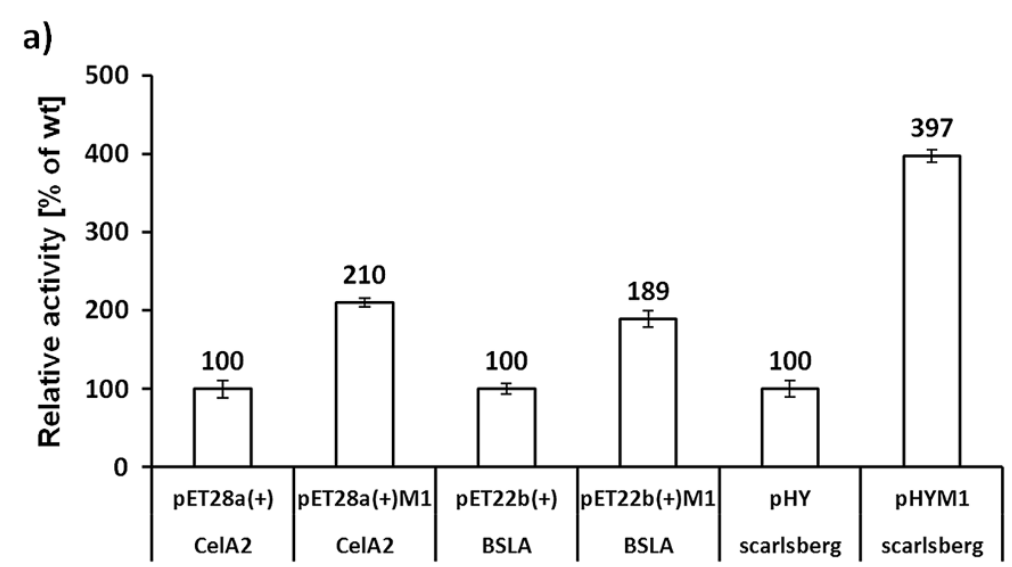

\section{b)}

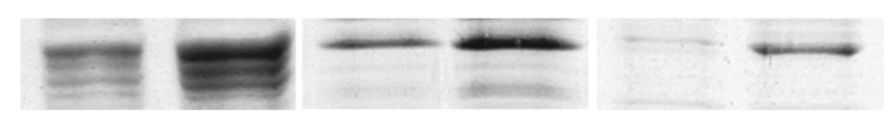

Figure 2 Activity studies and SDS-PAGE visualization of produced CeIA2, BSLA, subtilisin Carlsberg wild type. a) Activity measurements are performed with not optimized (left column) and mutagenized vector backbones (right column) in 96-well microtiter plate. Constructs with an M1 label habor an epMEGAWHOP optimized vector backbone; b) Visualization of production levels of CelA2 (proteins in supernatant of lysate), BSLA and subtilisin Carlsberg (proteins in culture supernatant after precipitation) by SDS-PAGE in combination with Coomassie brilliant blue staining. The reported relative activity values are the average of three $96-$ well microtiter plate measurements in which each construct was expressed 8 times per plate. Deviations are calculated from the corresponding mean values.

epMEGAWHOP strategy is a novel strategy to increase enzyme production by optimizing a vector backbone through mutagenesis and high-throughput screening. The epMEGAWHOP method (Figure 1) was validated by employing three different vector constructs with three different enzymes (cellulase: pET28a(+)-CelA2; lipase: pET22b(+)-BSLA; protease: pHY-scarlsberg). A single round of vector backbone mutagenesis and screening yielded significantly increased production levels for all three enzymes ( 2-fold for CelA2, $\sim 2$-fold for BSLA and $\sim 4$-fold for subtilisin Carlsberg). Control experiments through subcloning and sequencing confirmed that only the vector backbones were mutated with an average mutation frequency of $\sim 1.25$ mutations per $\mathrm{kb}$. The increase in cellulase, lipase and protease production demonstrate from our point of view that epMEGAWHOP is likely a general method for increasing enzyme production. This is supported by the selection of common expression systems which cover cytosolic (cellulase), periplasmatic (lipase), and extracellular production (protease) in combination with two industrially attractive bacterial hosts ( $E$. coli and B. subtilis). The main goal of this report is to validate

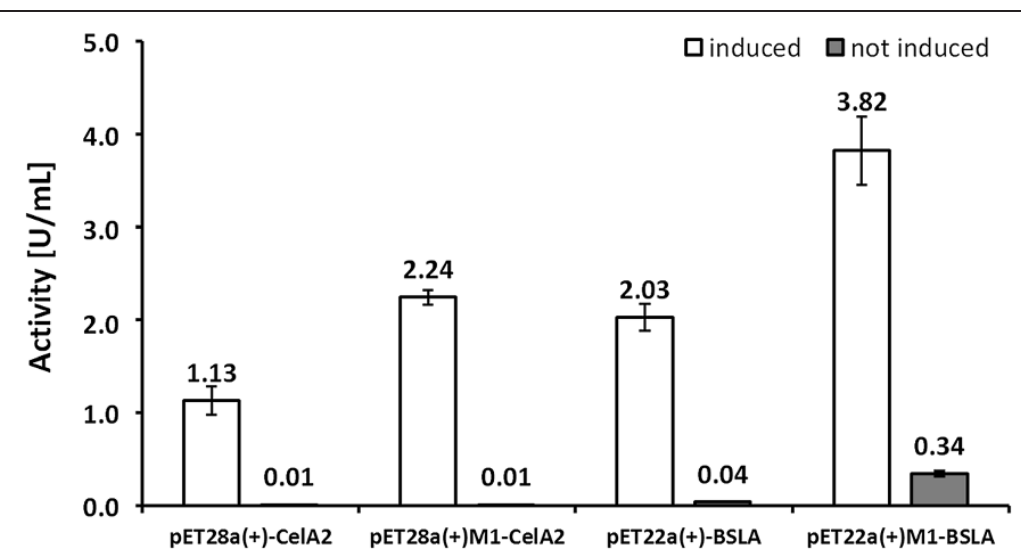

Figure 3 Functional study of the lacl repressor under induced (left bars) and non-induced (right bars) conditions employing pET28a (+)-CelA2, pET28a(+)M1-CelA2, pET22b(+)-BSLA and pET22b(+)M1-BSLA expression systems. Constructs with an M1 label harbor an epMEGAWHOP optimized vector backbone. Enzyme activity levels were determined with the corresponding screening systems in 96-well microtiter plate formats for CelA2 and BLSA. The reported values are the average of three 96 -well microtiter plate measurements in which each hydrolase was expressed 8 times per plate and deviations are calculated from the corresponding mean values. 
Table 2 Sequencing results of vector backbones that were subjected to epMEGAWHOP optimization

\begin{tabular}{|c|c|c|c|c|c|c|c|c|c|c|c|c|c|c|}
\hline \multicolumn{5}{|c|}{ pET28a(+)-CelA2 } & \multicolumn{5}{|c|}{ pET22b(+)-BSLA } & \multicolumn{5}{|c|}{ pHY-scarlsberg } \\
\hline \multirow[t]{2}{*}{ bp } & \multicolumn{3}{|c|}{ Substitution } & \multirow[t]{2}{*}{ Region } & \multirow[t]{2}{*}{ bp } & \multicolumn{3}{|c|}{ Substitution } & \multirow[t]{2}{*}{ Region } & \multirow[t]{2}{*}{ bp } & \multicolumn{3}{|c|}{ Substitution } & \multirow[t]{2}{*}{ Region } \\
\hline & wt & - & M1 & & & wt & - & M1 & & & wt & - & M1 & \\
\hline 488 & A & - & $\mathrm{T}$ & f1 origin & 123 & $\mathrm{~T}$ & - & C & T7 term & 209 & A & - & G & Tet \\
\hline 850 & G & - & C & Kan & 2007 & A & - & G & na & 684 & A & - & G & Tet \\
\hline 2233 & $\mathrm{~T}$ & - & C & pBR322 ori & 3701 & A & - & G & Tet & 1584 & $\mathrm{~T}$ & - & C & pTet \\
\hline 2396 & $\mathrm{~T}$ & - & C & na & 4563 & $\mathrm{~T}$ & - & C & lacl & 3238 & $\mathrm{~T}$ & - & C & pAMP \\
\hline 3170 & T & - & C & na & 4794 & C & - & $\mathrm{T}$ & lacl & 4221 & $\mathrm{~T}$ & - & C & na \\
\hline 5193 & A & - & T & T7 prom & & & & & & 4332 & A & - & - & ori-177 \\
\hline
\end{tabular}

The positions of the mutations in the corresponding vector backbones are based on the sequenced vector backbone prior epMEGAWHOP. Alignments of all three vector systems to the corresponding 'parents' are included in Additional file 1: Figure S1. Nucleotide position 1 is the base after the stop codon (ATT, TAA) of the inserted genes.

na: no corresponding function of the gene sequence could be assigned.

Kan/Tet: Kanamycin/Tetracyclin resistance gene.

pTET/pAMP: promoter region Tetracyclin/Ampicilin resistance gene (identified with a promoter prediction tool (Reese 2001)).

the epMEGAWHOP protocol for vector backbone optimization and not to elucidate in depth the interplay in the complex protein production machinery from the expression to the produced enzyme. The effect of randomly introduced mutations in the vector backbone has to our best knowledge not been investigated in a systematic manner.

Table 2 shows that functional regions such as antibiotic resistance, promoter, repressor or origin of replication were mutated. The mutations can be classified into three groups according to the region in the expression vector: 1) in the kanamycin/tetracycline resistance cassette; 2) once in the promoter and terminator region and 3) twice in the origin of replication. It is known that through the introduction of an expression vector into E. coli or other hosts for recombinant protein production, the native cell functions at many levels can be perturbed (e.g. ribosome functions, RNA turnover as well as energy and intermediary metabolism of the cell) (Bailey 1993; Hoffmann et al. 2002; Lin-Chao et al. 2006). This effect is very difficult, however, to predict or attribute to a specific change in the host metabolism, due to the complexity of the system. For example, a reduced but sufficient expression of the resistant marker could allow spending more metabolic resources into expressing the recombinant enzyme. On the other hand, a higher resistance marker expression could allow a higher specific growth rate of the cells which directly correlates with the rate of recombinant protein synthesis (Hoffmann and Rinas 2004).

Elucidating the influence of each mutation and each region on the cellulase, lipase, and protease production would include the introduction of the individual mutations in the parental vector backbones to gain a deeper understanding on the complex machinery from expression system to produced enzyme.
A main prerequisite for a successful epMEGAWHOP experiments is a reliable high-throughput screening system which allows an identification of improved expression variants. It is likely that the mutational load has to be optimized depending on the vector size; an average mutation frequency of 1.25 mutations per $1 \mathrm{~kb}$ prove to be efficient to increase enzyme production and all three sequenced vector backbones contained five to six mutations.

In essence, we developed a novel method to increase recombinant protein production based on the random mutagenesis of vector backbones (epMEGAWHOP). The general applicability of epMEGAWHOP was validated by increasing the protein production after one round of directed evolution for E. coli BL21-Gold (DE3)/ pET28a(+)-CelA2, E. coli BL21-Gold (DE3)/pET22b (+)-BSLA and B. subtilis DB104/pHY-scarlsberg. The main advantage of epMEGAWHOP is that it doesn't require a rational understanding of the expression machinery and can generally be applied to enzymes, expression vectors and related hosts. Changing expression vector or promoter systems to achieve higher enzyme yields often requires re-optimization of media composition, induction times and cell densities, together with expression and harvest time, in contrast to epMEGAWHOP. Overall, epMEGAWHOP is a robust, rapid and straight forward alternative and can be used for increasing recombinant protein production.

\section{Additional file}

Additional file 1: Figure S1. SDS-PAGE of produced cellulase (CelA2), lipase (BSLA) and protease (subtilisin Carlsberg). EV: empty vector control; WT: non-optimized vector constructs; M1: epMEGAWHOP optimized vector constructs. Red arrows indicate the bands of target proteins. Figure S2: Sequencing results: Alignments of all three vector systems 
compared to the corresponding 'parents': pET28a(+)-CelA2 \& pET28a(+) M1-CelA2.

\section{Competing interests}

The authors declare that they have no competing interests.

\section{Acknowledgements}

Authors thank Prof. Wolfgang Streit for providing the CelA2 amino acid sequence. This work was supported by the German Government through the Bundesministerium für Bildung und Forschung (FKZ 0315487A and FKZ 0315035A).

\section{Received: 24 April 2013 Accepted: 11 July 2013}

\section{Published: 26 July 2013}

\section{References}

Agudo R, Roiban GD, Reetz MT (2012) Achieving Regio- and Enantioselectivity of P450-Catalyzed Oxidative CH Activation of Small Functionalized Molecules by Structure-Guided Directed Evolution. ChemBioChem 13(10):1465-1473

Alquati C, De Gioia L, Santarossa G, Alberghina L, Fantucci P, Lotti M (2002) The cold-active lipase of Pseudomonas fragi. Heterologous expression, biochemical characterization and molecular modeling. Eur J Biochem 269 (13):3321-3328

Bailey JE (1993) Host-vector interactions in Escherichia coli. Adv Biochem Eng Biotechnol 48:29-52

Baneyx F (1999) Recombinant protein expression in Escherichia coli. Curr Opin Biotechnol 10(5):411-421

Boschker HTS, Cappenberg TE (1994) A Sensitive Method Using 4Methylumbelliferyl-ß-Cellobiose as a substrate to measure $(1,4)$-ß-glucanase activity in sediments. Appl Environ Microbiol 60(10):3592-3596

Brosius J, Erfle M, Storella J (1985) Spacing of the -10 and -35 regions in the tac promoter Effect on its in vivo activity. J Biol Chem 260(6):3539-3541

Cabrita LD, Dai W, Bottomley SP (2006) A family of E. coli expression vectors for laboratory scale and high throughput soluble protein production. BMC Biotechnol 6:12

Caspers M, Brockmeier U, Degering C, Eggert T, Freudl R (2010) Improvement of Sec-dependent secretion of a heterologous model protein in Bacillus subtilis by saturation mutagenesis of the $\mathrm{N}$-domain of the AmyE signal peptide. Appl Microbiol Biotechnol 86(6):1877-1885

Chernoglazov VM, Jafarova AN, Klyosov AA (1989) Continuous photometric determination of endo-1,4-ß-d-glucanase (cellulase) activity using 4methylumbelliferyl-ß-d-cellobioside as a substrate. Anal Biochem 179(1):186-189

Degering C, Eggert T, Puls M, Bongaerts J, Evers S, Maurer KH, Jaeger KE (2010) Optimization of protease secretion in Bacillus subtilis and Bacillus licheniformis by screening of homologous and heterologous signal peptides. Appl Environ Microbiol 76(19):6370-6376

DelMar EG, Largman C, Brodrick JW, Geokas MC (1979) A sensitive new substrate for chymotrypsin. Anal Biochem 99(2):316-320

Fallah-Araghi A, Baret JC, Ryckelynck M, Griffiths AD (2012) A completely in vitro ultrahigh-throughput droplet-based microfluidic screening system for protein engineering and directed evolution. Lab Chip 12(5):882-891

Funke SA, Eipper A, Reetz MT, Otto N, Thiel W, Van Pouderoyen G, Dijkstra BW, Jaeger KE, Eggert T (2003) Directed Evolution of an Enantioselective Bacillus subtilis Lipase. Biocatal Biotransform 21(2):66-73

Gustafsson C, Govindarajan S, Minshull J (2004) Codon bias and heterologous protein expression. Trends Biotechnol 22(7):346-353

Hanahan D (1983) Studies on transformation of Escherichia coli with plasmids. J Mol Biol 166(4):557-580

Heyland J, Blank LM, Schmid A (2011) Quantification of metabolic limitations during recombinant protein production in Escherichia coli. J Biotechnol 155 (2):178-184

Hoffmann F, Rinas U (2004) Stress induced by recombinant protein production in Escherichia coli. Adv Biochem Eng Biotechnol 89:73-92

Hoffmann F, Weber J, Rinas U (2002) Metabolic adaptation of Escherichia coli during temperature-induced recombinant protein production: 1 Readjustment of metabolic enzyme synthesis. Biotechnol Bioeng 80(3):313-319

Hughes S, Riedmuller S, Mertens J, Li X-L, Bischoff K, Qureshi N, Cotta M, Farrelly $P$ (2006) High-throughput screening of cellulase $F$ mutants from multiplexed plasmid sets using an automated plate assay on a functional proteomic robotic workcell. Proteome Sci 4:10

Jana S, Deb JK (2005) Strategies for efficient production of heterologous proteins in Escherichia coli. Appl Microbiol Biotechnol 67(3):289-298

Kabisch J, Thurmer A, Hubel T, Popper L, Daniel R, Schweder T (2012) Characterization and optimization of Bacillus subtilis ATCC 6051 as an expression host. J Biotechnol 163:97-104

Kawamura F, Doi RH (1984) Construction of a Bacillus subtilis double mutant deficient in extracellular alkaline and neutral proteases. J Bacteriol 160(1):442-444

Khushoo A, Pal Y, Singh BN, Mukherjee KJ (2004) Extracellular expression and single step purification of recombinant Escherichia coli l-asparaginase II. Protein Expr Purif 38(1):29-36

Kintses B, Hein C, Mohamed MF, Fischlechner M, Courtois F, Laine C, Hollfelder F (2012) Picoliter cell lysate assays in microfluidic droplet compartments for directed enzyme evolution. Chem Biol 19(8):1001-1009

Kirk O, Borchert TV, Fuglsang CC (2002) Industrial enzyme applications. Curr Opin Biotechnol 13(4):345-351

Laemmli UK (1970) Cleavage of structural proteins during the assembly of the head of bacteriophage T4. Nature 227(5259):680-685

Lehmann C, Sibilla F, Maugeri Z, Streit WR, Domínguez de María P, Martinez R, Schwaneberg U (2012) Reengineering CelA2 cellulase for hydrolysis in aqueous solutions of deep eutectic solvents and concentrated seawater. Green Chem 14(10):2719-2726

Li A, Kato Z, Ohnishi H, Hashimoto K, Matsukuma E, Omoya K, Yamamoto Y, Kondo N (2003) Optimized gene synthesis and high expression of human interleukin-18. Protein Expr Purif 32(1):110-118

Lin-Chao S, Chen WT, Wong TT (2006) High copy number of the pUC plasmid results from a Rom/Rop-suppressible point mutation in RNA II. Mol Microbiol 6(22):3385-3393

Martinez R, Jakob F, Tu R, Siegert P, Maurer KH, Schwaneberg U (2013) Increasing activity and thermal resistance of Bacillus gibsonii alkaline protease (BgAP) by directed evolution. Biotechnol Bioeng 110(3):711-720

Miyazaki K (2003) Creating random mutagenesis libraries by megaprimer PCR of whole plasmid (MEGAWHOP). Meth Mol Biol 231:23-28

Miyazaki K (2011) MEGAWHOP cloning: a method of creating random mutagenesis libraries via megaprimer PCR of whole plasmids. Methods Enzymol 498:399-406

Rai M, Padh H (2001) Expression systems for production of heterologous proteins. Curr Sci 80(9):1121-1128

Ruff AJ, Dennig A, Wirtz G, Blanusa M, Schwaneberg U (2012) 1. Flow Cytometer-Based High-Throughput Screening System for Accelerated Directed Evolution of P450 Monooxygenases. ACS Catalysis 2(12):2724-2728

Sass S, Kadow M, Geitner K, Thompson ML, Talmann L, Bottcher D, Schmidt M, Bornscheuer UT (2012) A high-throughput assay method to quantify Baeyer-Villiger monooxygenase activity. Tetrahedron 68(37):7575-7580

Shirai K, Jackson RL, Quinn DM (1982) Reciprocal effect of apolipoprotein C-II on the lipoprotein lipase-catalyzed hydrolysis of p-nitrophenyl butyrate and trioleoylglycerol. J Biol Chem 257(17):10200-10203

Shivange AV, Marienhagen J, Mundhada H, Schenk A, Schwaneberg U (2009) Advances in generating functional diversity for directed protein evolution. Curr Opin Chem Biol 13(1):19-25

Sokol PA, Ohman DE, Iglewski BH (1979) A more sensitive plate assay for detection of protease production by Pseudomanas aeruginosa. J Clin Microbiol 9(4):538-540

Tee KL, Schwaneberg U (2007) Directed evolution of oxygenases: screening systems, success stories and challenges. Comb Chem High Throughput Screen 10(3):197-217

Terpe K (2006) Overview of bacterial expression systems for heterologous protein production: from molecular and biochemical fundamentals to commercial systems. Appl Microbiol Biotechnol 72(2):211-222

Thomas JG, Ayling A, Baneyx F (1997) Molecular chaperones, folding catalysts, and the recovery of active recombinant proteins from $E$. coli. To fold or to refold. Appl Biochem Biotechnol 66(3):197-238

Tu R, Martinez R, Prodanovic R, Klein M, Schwaneberg U (2011) A flow cytometrybased screening system for directed evolution of proteases. J Biomol Screen 16(3):285-294

Vojcic L, Despotovic D, Martinez R, Maurer KH, Schwaneberg U (2012) An efficient transformation method for Bacillus subtilis DB104. Appl Microbiol Biotechnol 94(2):487-493 
Westers L, Westers H, Quax WJ (2004) Bacillus subtilis as cell factory for pharmaceutical proteins: a biotechnological approach to optimize the host organism. Biochim Biophys Acta 1694(1-3):299-310

Xue GP, Johnson JS, Bransgrove KL, Gregg K, Beard CE, Dalrymple BP, Gobius KS, Aylward JH (1997) Improvement of expression and secretion of a fungal xylanase in the rumen bacterium Butyrivibrio fibrisolvens OB156 by manipulation of promoter and signal sequences. J Biotechnol 54(2):139-148 Yedavalli P, Rao NM (2013) Engineering the loops in a lipase for stability in DMSO. Protein Eng Des Sel 26(4):317-324

doi:10.1186/2191-0855-3-39

Cite this article as: Jakob et al:: Increasing protein production by directed vector backbone evolution. AMB Express 2013 3:39.

\section{Submit your manuscript to a SpringerOpen ${ }^{\circ}$} journal and benefit from:

- Convenient online submission

- Rigorous peer review

- Immediate publication on acceptance

- Open access: articles freely available online

- High visibility within the field

- Retaining the copyright to your article

Submit your next manuscript at $>$ springeropen.com 